\title{
Research on the ecological environment in the process of industrialization
}

\author{
Guo Xian \\ Xi'an International University, Shaanxi, Xi'an, 710077, China
}

Keywords: Industrialization; Ecological environment; Pollution; Development

\begin{abstract}
Since the reform and opening up, China's economic development has made great achievements in the process of industrialization, more and more quickly, but the problem of ecological environment has become more and more prominent. The main position of China's industrial development is the city, while the city as people gathered in the heart, is directly affected by the quality of the ecological environment objectively. Speaking, China's ecological environment in the process of industrialization has been largely destroyed, the problem of environmental pollution has seriously affected people's quality of life, also have a negative impact on building a harmonious socialist society in China, under this background, the state proposed industrial development and ecological environment The basic national policy of environment coordinated development. Adhere to the scientific development view, and actively explore ways of application of high technology in the development of circular economy, the construction of a new industrial system, construction of a conservation oriented society, is the right way of sustainable development of China's social health.
\end{abstract}

\section{Analysis of the impact of industrialization process on ecological environment}

\subsection{Characteristics of industrialization}

In our country's economic system, industry is the first industry, is an important material production sector, but also the economic and social development of the leading industry. The most important new China establishment, basic industry is completely blank, for the country to more prosperous democracy, the importance of regulating the process of industrialization must be stronger, and from the overall development of the whole the world experience, the characteristics of industrialization is to set up and destroyed, the so-called establishment refers to the construction of a complete service to the national development of the material production system, the damage refers to damage to the ecological environment which will form the natural state of the inevitable in the process of establishing a material production system, from the debate Law point of view, the two are interdependent. In the early stage of industrialization, in order to maximize production efficiency, bound for the destruction of the ecological environment problems are ignored, with the increasing profits of material production, the country's economic construction will make significant achievements, people's living standard will come naturally this will require improved, for the ecological environment becomes high. The current level of industrialization of our country has developed to a very advanced level of ecological and environmental problems have become a serious obstacles the process continues to accelerate, the protection of the ecological environment has become a basic national policy and administration in China An important function of government.

\subsection{Industrialization practice}

From the point of view of the world, industrial development has experienced a history of hundreds of years, the damage of ecological environment has been proved, and the ecological environment is more and more important for human survival quality, therefore, the ecological environment problems in the process of industrialization has aroused worldwide attention in China. The industrial development time only lasts for a few decades, but the scale and speed of development, the ecological environment for the extent of the damage is incalculable, from the 
relevant statistical data, China is already one of the world's most polluted countries. From the development of China's industry practice, there are obvious resources The characteristics of intensive, the natural ecological environment in the forest, water, land and other elements to mining and processing of predatory, irreversible ecological environment resources in huge losses, the direct cause of the increase of natural disasters at present, air quality down. Since the reform and opening up, China's rapid industrialisation fast the whole world lives, economic development in certain achievement at the same time, we should also recognize that the development of China's industrialization is at the cost of great damage to the ecological environment, the current thinking of one-sided pursuit of the interests of the traditional industrial development, and actively explore the process of industrialization and ecological The new road of harmonious development of the environment.

\section{City in the process of industrialization of ecological environment deterioration}

\subsection{The city's ecological environment vulnerability}

The city is the inevitable outcome of the development of human society, on behalf of the development of human society has entered a relatively high stage, there is a foundation for the development of city industrialization, and the industry is using various means to obtain material from natural resources, intensive processing, elimination of waste output. The city is the human life the required material production center, but also the city's ecological environment vulnerability is very strong, so it is also the source of environmental pollution and destruction. The city is gathering population, so the ecological system is a system with the rapid development of the population to replace or limit other biological development, Artificial features are very obvious, every city has a lot of artificial facilities superimposed on the natural environment, with the continuous expansion of the city, the population also increased sharply, but compared to other biological groups of people the number will be less and less, these are caused by the city ecological environment more fragile ecological environment. Nature itself has to absorb the cleaning capacity, but with the changing physical city's ecological environment, the original non destruction and pollution free adjustment mechanism is obviously too weak, the haze phenomenon nationwide is proof.

\subsection{The deviation of guiding ideology}

In the process of China's industrialization, know the thought has some problems, such as lack of Scientific Outlook on Development's guidance, the lack of overall thought and the three aspects of the lack of private industrial development guidance. First of all, in the city of our country in the process of development, the demand of the industrial development is often the only pursuit of development effect. With the rapid growth as the goal, and for its as a result of the destruction of the ecological environment is blind to the short-term effect, the speed of industrial development does have a certain degree of speeding up, but from the long-term interests, the decline in the quality of the deterioration of the ecological environment will cause living space in the city, which not only Just have an impact on the residents, for the development of the industry will also bring great restrictions. Second, taking into account the lack of overall thought, led to the growth of industrial development are too extensive, high consumption, high investment development mode caused a great waste of natural resources, the relevant data shows that since the reform and opening-up of our country, though the development has made great achievements, but the total amount of environmental resources consumed is prohibitively high. Finally, after China's entry into the market economy from the planned economy era, private enterprises ushered in the climax of the development, but the development of the lack of guidance and effective supervision, many private chemical industry, smelting, building The destruction of the natural ecological environment is especially serious for the enterprises such as timber and mineral resources

\subsection{Policy system and implementation deviation}

In the process of China's industrialization, long-standing policy system and implementation 
problems, the problems caused by the destruction of the ecological environment, the specific performance of resource development policies in place and law execution is not in place in two aspects. First, resource development policy aspect, coal, oil and natural gas resources in the industry China has a very special status in the national policy level also attaches great importance to the development of resources industry, made some relevant policies on the industry, but from the current actual situation, the real implementation of the policy is not in place, the development of the right to limit the execution status of the confusion caused by the lack of industry status quo, The interests of participants will be regarded as an opportunity to get rich, full of overt and covert mining caused great damage to the natural ecological environment. And then look at the laws and regulations as a matter of fact, China is quite sound on the law to protect ecological environment, but the specific implementation is not in place, because a lot of places our country is the existence of local protectionism, laws and regulations will be greatly reduced in the specific implementation of the time, which leads to the illegal behavior in the frequent industrial development, power generation method, in a statement on behalf of the law phenomenon in the local government's industrial development appear very common, which resulted in a law enforcement difficult problem In addition, in order to improve their political achievements, local governments tend to abandon their principles and introduce some heavy polluting enterprises abroad, which are too persistent in pursuit of economic interests, resulting in the destruction of the ecological environment

\section{Industrial Development and ecological environmental protection win-win strategy conception}

\subsection{Establish Scientific Outlook on Development}

In the industrialization process, people just take the nature as object request, but natural resources are non renewable, excessive pursue economic interests while ignoring the ecological benefits of the concept of industrial development, have development effect in short-term, but can not guarantee the long period of human health and sustainable development. To realize the relationship between man and nature, establish the scientific concept of development, in order to ensure the healthy development of society, to completely abandon the past development of light weight concept, fully aware of the importance of the natural ecological environment for people. At present, there are many local governments that economic growth is the development of the concept of development is not scientific, to establish the scientific concept of development, the development of system construction of green high GDP, so as to ensure the progress of the society, with the construction of the harmonious society at present.

\subsection{Establish a new industrialization system}

With the development of science and technology change rapidly, China's economic development has also ushered in new opportunities and challenges, the traditional development mode of the industrial enterprises have been struggling in the current context, must be adjusted to adapt to the new situation. In order to build the ecological environment system of new-type industrialization as the foundation, is a an important direction of the current economic development in China, with the progress of science and technology as the support for the optimization of the industrial structure, the effective use of resources and emphasizes the construction of the ecological environment, promote the intensive, build a conservation oriented society, is the need of the economic development of China. The establishment of new industrialization system, is the core of ecological environment system The establishment of the market mechanism and the introduction of the concept of ecological environment construction into the market can fundamentally strengthen the balance process between industrial development and ecological environment

\subsection{Developing circular economy}

Waste pollution is the ecological environment of our country in a more prominent issue, all kinds of waste treatment industry brought about how to promote the development of the current 
ecological environment construction and industrial development are considered a key issue in the circular economy. The proposed concept, pointed out a direction to solve the problem of waste treatment the construction, decomposition of industrial waste utilization is an important content in the adjustment of the industrial structure. China is a country with a large population, the number of storage capacity of natural resources and population can not match, build a conservation oriented society, and actively explore the development mode of circular economy, which can not only meet the current needs of economic development in china, It can save more natural resources for future generations.

\subsection{Strengthen policy implementation efforts}

The current ecological environment in our country has suffered serious damage, which requires treatment, although the state at the policy level for environmental governance has made a lot of tilt, but from the specific implementation, the effect is not very good, the main reason is the implementation of the policy system of rigid enough. The establishment of resource development ecological compensation system adhere to the "who who who use compensation, benefit or harm to anyone who pays" principle, the establishment of ecological tax system, unified, unified management system, so as to strengthen the policy system. The rigidity of governance from the industrial point of view, to comprehensive utilization of finance, credit and price control means to create conditions favourable for the development of corporate governance, Strict control of resource consumption, pollution enterprises, and the "supporting a" normalization, guarantee policy system can be effectively implemented.

\subsection{Learn advanced experience}

China's ecological environment protection work has been carried out for a period of time, because of the actual situation and the investment of each local government's situation is different, so in effect among regions showed a great difference, which requires a relatively backward region should actively learn from the experience of the performance of the advanced regions. At present, our country has reached the a hitherto unknown height of the degree of attention to ecological replacement problem, there are many areas of work and achieved good results, this experience is very valuable, should be summarized and analyzed, and then spread in the whole country. Of course, the actual situation and the characteristics of each area of its own, simple The duplication is unscientific and impractical, which requires that the backward areas should not only copy mechanically, but also think more deeply with their own situations

\section{Conclusion}

Industrialization is the necessary factor to promote the development of human society, the ecological environment is the natural basis for the survival of human society, is the effect on people, so we should actively seek the inner balance of the two. From a global perspective, the development of China's industrialization has made remarkable achievements, but also cannot be objectively based it is particularly strong, so continue to strengthen the pace of the industrialization process, in the future for a long period of time, but also is an important goal of China's economic development. At present, China is one of the world's most polluted countries, the destruction of the ecological environment has seriously affected the normal life of the people Life, construction of comprehensive management and ecological environment which requires must consider pollution. How to find the best balance point of industrial development and construction of ecological environment, but also in the next period of time is a difficult problem in the economic development of our country, require extensive discussion and concerted efforts of all sectors of the community, and actively explore solutions effective.

\section{References}

[1] Zhen Jiang Hong, Li Lingmin, He Sunpeng, Luo Shasha. Study on ecological environment 
impact in the process of industrialization in Inner Mongolia and its response [J]. Journal of arid land resources and environment, 2015,29 (11): 86-92.

[2] Zhao Ao. Study on interactive response between industrialization process and ecological environment load in Liaoning [J]. Journal of Nanchang Teachers College, 2017,38 (01): 23-26+66.

[3] Wu Shuo. Three dimensional study and Enlightenment of ecological environment governance in the process of industrialization in the United States [D]. Beijing Forestry University, 2014.

[4] $\mathrm{Xu}$ Chenglong. Study on industrial structure adjustment and its ecological effects under environmental regulation [D]. Shandong Normal University, 2015. 